REVISTA DE LITERATURA E CULTURA RUSSA

\title{
A era do "estranhamento": o Formalismo Russo e o conhecimento humanístico contemporâneo
}

The Age of "Estrangement": the Russian Formalism and the Modern Humanistic Knowledge 


\section{A era do "estranhamento": o Formalismo Russo e o conhecimento humanístico contemporâneo}

Resumo: Esta resenha apresenta ao leitor brasileiro o livro $A$ era do estranhamento: o Formalismo Russo e o conhecimento humanístico contemporâneo, publicado em 2017. 0 livro é resultado do evento internacional ocorrido em Moscou em 2013, que estabeleceu e celebrou o centenário do Formalismo Russo. A obra apresenta contribuições de pesquisadores do mundo todo, revisa e expande, consideravelmente, os limites de alcance de uma das mais importantes escolas de crítica literária do século XX.

\begin{abstract}
This review introduces to the Brazilian reader the book The Age of Estrangement: the Russian Formalism and the Modern Humanistic Knowledge, published in Moscow. This book is a result of an international meeting that happened in 2017, which established and celebrated the Russian Formalism centenary. It presents articles from scholars around the world, reconsiders and expands, substantially, the limits of that which was one of the most important literary criticism movements in the beginnings of the 20th century.
\end{abstract}

Palavras-chave: Formalismo Russo; Estranhamento (ostraniénie); Centenário Keywords: Russian Formalism; Estrangement (ostranenie); Centenary 
* Professor do Centro Universitário Fundação Santo André e da Escola Técnica Estadual Jornalista Roberto Marinho.

Pós-doutorando do

Departamento de Letras Orientais da Faculdade de Filosofia, Letras e Ciências Humanas da Universidadede São Paulo; https://orcid.org/0000-0002-99603332; valvaz@usp.br

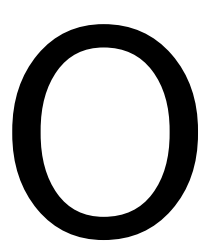

leitor interessado nas questões concernentes ao Formalismo Russo, uma das mais importantes e originais correntes de crítica literária do século $\mathrm{XX}$, já dispõe de uma nova fonte onde se atualizar. Trata-se de $A$ era do "estranhamento": o Formalismo Russo e o conhecimento humanístico contemporâneo, lançado em 2017 pela editora russa Nova Revisão Literária. O título faz referência à palavra ostraniénie (estranhamento), cunhada por Viktor Chklóvski em 1917 em "A arte como procedimento" para se referir aos efeitos perceptivos que determinadas obras produzem no leitor. ${ }^{1}$

Dividido em oito seções temáticas, o volume compreende 670 páginas e contém 85 artigos de pesquisadores de diferentes instituições ao redor do mundo. A costumeira abordagem histórica, tão comum em manuais e antologias do movimento, cede lugar a enfoques diversos. Sob o signo da interdisciplinaridade, a antologia procura correlacionar ao Formalismo uma miríade de saberes e temas que vão da semiótica (russa e francesa) à folclorística, passando por áreas como história da arte, intertextualidade, filosofia da ciência, direito etc.

A maior parte dos ensaios aqui reunidos provém de comunicações apresentadas ao Congresso Internacional dos 100 Anos da Escola Formalista Russa, ocorrido em Moscou entre 25 e 29 de agosto de 2013. Voltarei a este tema mais adiante.

O livro, além de ampliar os limites da teoria formalista para muito além da abordagem do texto literário, vem pôr fim a uma velha querela que perdurou por quase um século entre duas instituições russas que havia muito disputavam a posição de fundadoras do Formalismo. Por muito tempo os historiadores do movimento se viram frente à dificuldade de fixar "onde" e

1 Para maiores detalhes sobre o conceito de estranhamento veja principalmente os dois números que a revista Poetics Today (vol. 17, n. 4, de 1996 e vol. 26, n. 4, de 2005) dedicou ao conceito. Veja-se também o ensaio "Arte como procedimento' - 100 anos depois", no v.9, n. 12, de 2018, da revista eletrônica RUS. 
"quando" ele teria tido origem. De um lado, havia os que creditavam sua fundação a um grupo de intelectuais de Petrogrado, capitaneado por um rapaz de vinte e poucos anos, muito ativo e um tanto "superficial": Viktor Chklóvski. Vista por este prisma, a fundação da Sociedade para o Estudo da Linguagem Poética (OPOIAZ), em 1916, a partir da iniciativa de Chklóvski, Iúri Tyniánov, Boris Tomachévski, Boris Eikhenbaum e outros, vinha sendo considerada o acontecimento que fundou o movimento. Por outro lado, perfilavam os que defendiam que a pedra de toque tinha sido lançada por Roman Jakobson, em 1915, no âmbito das atividades do Círculo Linguístico de Moscou (CLM), grupo do qual foi um dos fundadores e o primeiro presidente. Embora haja muitos pontos em comum entre os dois grupos - e o principal é o fato de muitos de seus membros pertencerem às duas associação ao mesmo tempo - suas atividades se diferenciam particularmente quanto aos objetos de interesse de cada um: enquanto os teóricos da OPOIAZ dedicaram-se a elementos de Teoria Literária (enredo, estranhamento, personagem, fabula, siujet, gesto fônico, skaz etc.), o CLM focou na Linguística, particularmente em dois ramos desta: a Fonologia e a Dialetologia ${ }^{2}$. Quando a questão envolvia saber a qual deles creditar a fundação da escola, as vantagens sempre estiveram do lado dos linguistas moscovitas, isto por algumas razões que veremos a seguir.

O fato de o CLM - cujas origens remontam à Comissão Moscovita de Dialetologia, fundada em 1904 - estar burocraticamente associado à Universidade de Moscou exigiu de seus membros a obrigação de registrar em atas seus encontros e atividades. Quando os historiadores buscaram as raízes do movimento, essa documentação rica e vasta representou muito. $E$ isso por muito tempo foi encarado como uma vantagem do CLM sobre o grupo da OPOIAZ, que não dava a mínima para procedimentos burocráticos. Para se ter uma ideia, as reuniões da OPOIAZ eram extremamente informais, e até 1924 seus in-

2 Veja-se as principais diferenças entre os sois grupos no ensaio de llya Kalinin: "Viktor Shklovsky vs. Roman Jakobson. Poetic Language or Poetic Function of Language". Revista Enthymema, n. 19, 2017. Disponível também em https://riviste.unimi.it/index.php/enthy-mema/article/view/9427/8901. 
tegrantes não dispunham de local fixo onde pudessem se reunir. Por diversas vezes Óssip Brik, um rico herdeiro e advogado comunista de Petrogrado, intercedeu no sentido de promover o grupo, emprestando seu apartamento para as reuniões, além de viabilizar financeiramente a publicação dos dois primeiros volumes de ensaios do grupo. Mais tarde, o próprio Brik viria a ser incluído no grupo formalista de Petrogrado, com um estudo célebre sobre o ritmo na poesia.

Outro argumento que contou a favor da ala moscovita foi o fato de a primeira antologia estrangeira de ensaios de críticos formalistas - publicada em 1965, na França, com organização e tradução do búlgaro imigrado Tzvetan Todorov - conter uma introdução de Jakobson, dando a entender que o círculo do qual fizera parte é que deveria ser considerado o fundador do movimento.

Em 1920 Jakobson deixou suas atividades no CLM e emigrou para a Tchecoslováquia como tradutor de uma missão da Cruz Vermelha soviética e, em 1939, na condição de refugiado do nazismo, seguiu para os Estados Unidos, aí se consagrando como um dos linguistas mais eminentes da cena intelectual do século XX e também como o porta-voz do Formalismo no Ocidente. Os vários representantes do movimento que permaneceram na Rússia sempre desconfiaram do partidarismo de Jakobson ao se referir à escola. Um desses críticos, embora com pouca participação entre os formalistas, foi Viktor Jirmúnski, que, em 1939, em uma missiva a Chklóvski, escreveu: "Roman Jakobson deforma conscientemente esta história [a história do Formalismo Russo] nas edições estrangeiras, apresentando [o Formalismo Russo] à sua maneira". ${ }^{3}$ Já Chklóvski, opositor direto de Jakobson na corrida pela paternidade do movimento, sempre desconfiou deste, chegando a afirmar, em sua correspondência privada com amigos e parentes, que Jakobson fazia "espionagem soviética" em Praga. Numa carta de 20 de julho de 1969 a Nikita Chklóvski-Kordi, seu neto, Viktor Chklóvski escreve: "Hoje, meu ex-amigo Roman Jakobson afirma que foi ele - e não eu - quem criou o chamado 'método for-

3 JIRMÚNSKI apud SANMARTÍN ORTÍ, Pau. Otra historia del formalismo ruso. Madrid: Lengua de trapo, 2008. p. 32. 
mal', o qual deu origem ao Estruturalismo". ${ }^{4}$ Mais recentemente, em 2008, o pesquisador Pau Sanmartín Ortí, de Valencia, Espanha, ao propor "uma outra história do Formalismo Russo", também chamou a atenção para o fato de Jakobson manipular habilmente a cronologia de eventos e publicações de modo a antepor as atividades do Círculo Linguístico de Moscou às da OPOIAZ.

Jakobson interpretava a questão da seguinte maneira: para ele, o grupo de Petrogrado não deveria entrar para a história do Formalismo Russo antes de 1916, ocasião em que é publicada a primeira coletânea de artigos do grupo. No entanto, se este for o critério válido, o próprio Círculo Linguístico de Moscou ficaria fora da história, uma vez que seus membros nunca chegaram a publicar uma obra de caráter coletivo, que expusesse as tendências e os estudos do grupo. Em 1919, os representantes da OPOIAZ já haviam publicado três volumes com trabalhos de cada um de seus membros, ao passo que do grupo de Moscou nada tinha vindo a lume. ${ }^{5}$

Outro argumento que aponta o favoritismo de Jakobson no sentido de se firmar como pai fundador da escola formalista encontra-se em Child of a Turbulent Century (2006) a autobiografia de Victor Erlich. ${ }^{6}$ Erlich desenvolveu seu doutorado sob a orientação de Jakobson ${ }^{7}$ na Universidade de Columbia, na década de 1950, e em Child of a Turbulent Century recorda a experiência ímpar de ter sido aluno de um dos membros mais ilustres do Formalismo Russo. No capítulo "Back to School: Russian Formalism with Roman Jakobson", com o distanciamento histórico necessário, Erlich recorda algo além das lembranças felizes: "ao contar a história formalista-estruturalista, fui reconhecidamente influenciado pela posição do meu orientador em relação a alguns dos protagonistas [do Formalismo Russo]. Os sentimentos emaranhados de Jakobson em relação a Chklóvski podem ter influenciado minha apresentação do porta-voz espiritual do Formalismo." (p. 132.)

Mas essas disputas, a bem da verdade infrutíferas e segmentadoras, chegaram ao fim em 2013, quando os responsáveis pela organização do evento que deu origem ao livro aqui 
apresentado estabeleceram 1913 como o ano de surgimento do Formalismo. O filólogo Viatchesláv Vsevolódovitch Ivánov, morto em 2017, foi o responsável direto pela fixação do ano de nascimento da escola, ou seja, o mérito não ficou nem com o CLM, nem com a OPOIAZ, pois a data retroage a ambos. Sabendo da importância e das implicações do Formalismo para muito além da crítica literária e de sua difusão mundo afora, Ivánov, desde o outono russo de 2012, já se movimentava entre vários centros de pesquisa de Moscou em busca de suporte para o centenário; por esta e outras tantas razões, ele foi principal o homenageado do evento ${ }^{8}$.

Mas, por que 1913? Porque foi no dia 23 de dezembro deste ano que Chklóvski - o enfant terrible do movimento, com então 20 anos de idade - leu para um grupo de poetas e artistas de Petrogrado, no cabaré literário Brodiátchaia Sobáka (O Cão Vira-lata), "O lugar do futurismo na história da língua", uma espécie de panfleto contendo suas considerações sobre a arte futurista. Depois de alguns retoques, o panfleto foi publicado um ano depois, com o título de "Ressurreição da palavra". Ainda que não utilize seu conceito mais famoso e prolífico, a noção de estranhamento (ostraniénie) já se insinua sub-repticiamente no texto, só não é nomeada. A apresentação pública causou boa impressão aos ouvintes, conquanto ele nunca tenha sido considerado membro de nenhum dos grupos futuristas de então. Sua participação foi particularmente importante pelo fato de ele representar uma espécie de porta-voz da ciência universitária e também por expressar um ponto de vista externo ao Futurismo, necessário, porém, à consolidação da

80 evento nasceu da parceria entre seis grandes instituições de ensino superior russas, entre elas a Escola de Economia e a Universidade Estatal Russa para as Humanidades. 0 caderno de resumos das comunicações do Congresso Internacional dos 100 Anos da Escola Formalista Russa contém nada menos que 126 apresentações, muitas acontecendo ao mesmo tempo, o que obrigou o público a uma verdadeira maratona pelos corredores universitários, quando não pelas ruas e avenidas de Moscou, congestionadas como sempre. Uma ala renomada de teóricos e professores com obras consagradas sobre o tema - Aage Hansen-Löve, atualmente na Universidade de Munique, o próprio Viatchesl'sv V. Ivánov, da Universidade Estatal de Moscou, John E. Bowlt, da Universidade do Sul da Califórnia, Eero Tarasti, da Universidade de Helsinque, e Catherine Depretto, da Sorbonne - foram os primeiros a apresentar suas comunicações. A sensação que fica é a de que esses mestres, com carreiras sólidas em renomadas universidades russas e estrangeiras, passavam naquele momento o bastão à nova safra de jovens pesquisadores. 


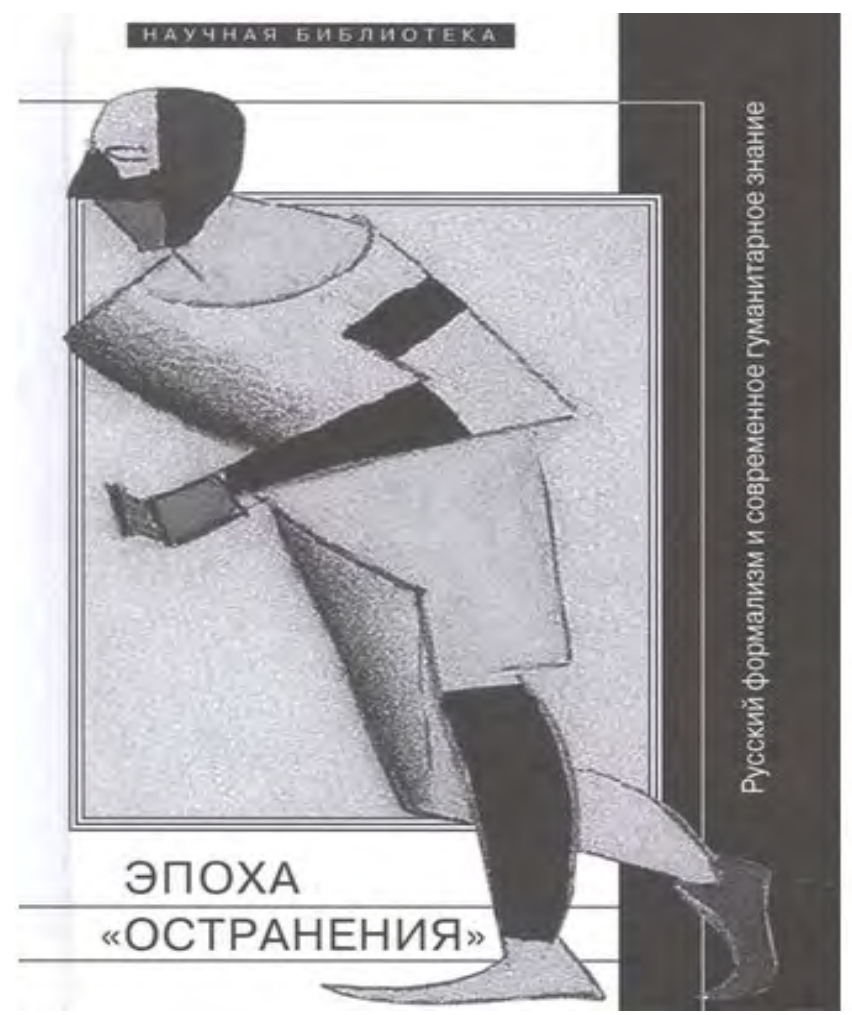

prática artística nascente. Como sempre ocorre, muitos dos que assistiram suas colocações consideraram-no um oportunista e um franco atirador, fama que, por essas e outras razões, carregou pela vida toda.

Como informado, $A$ era do "estranhamento nasceu de comunicações realizadas no centenário do Formalismo. A grande quantidade de trabalhos com vistas à publicação fez com que os organizadores da coletânea se orientassem por uma perspectiva qualitativa, escolhendo os que melhor traduziam os propósitos e tendências do evento. Evidentemente, isso acabou deixando de fora uma gama considerável de contribuições cujos resumos ainda podem ser encontrados na internet.

A organização do volume ficou a cargo de Igor Pilshchikov, atualmente professor no Departamento de Línguas e Culturas Eslavas da Universidade da Califórnia, em Los Angeles, e Yan Levchenko, hoje professor de Inglês e Estoniano na Faculdade de Ciências Humanas da Escola Superior de Economia, em Moscou. Ambos assinam a introdução e ensaios que integram a coletânea.

A primeira seção temática é "O século da teoria formalista: sua atualidade"; aqui o leitor encontrará ensaios de eslavistas consagrados como Peter Steiner, Aage Hansen-Löve, Viatchesláv Vsevolódovitch Ivánov, entre muitos outros. O propósito, explícito no próprio título, é apresentar a atualidade da teoria formalista russa. $O$ ensaio de Ivánov apresenta as interpretações que o sistema crítico formalista recebeu e tem recebido no âmbito das ciências dos séculos XX e XXI; já Hansen-Löve tratou das "semelhanças de família" entre perspectivas formalistas e o logocentrismo, a virada linguística do século XX e o Pós-estruturalismo, tendo como guia espiritual Roman Jakobson. Peter Steiner, por sua vez, encontrou uma fecunda analogia entre o estranhamento (ostraniénie) de Chklóvski, a teoria do direito de Carl Schmitt e a filosofia da ciência praticada por Karl Popper. 
A segunda, denominada "O Formalismo Russo no
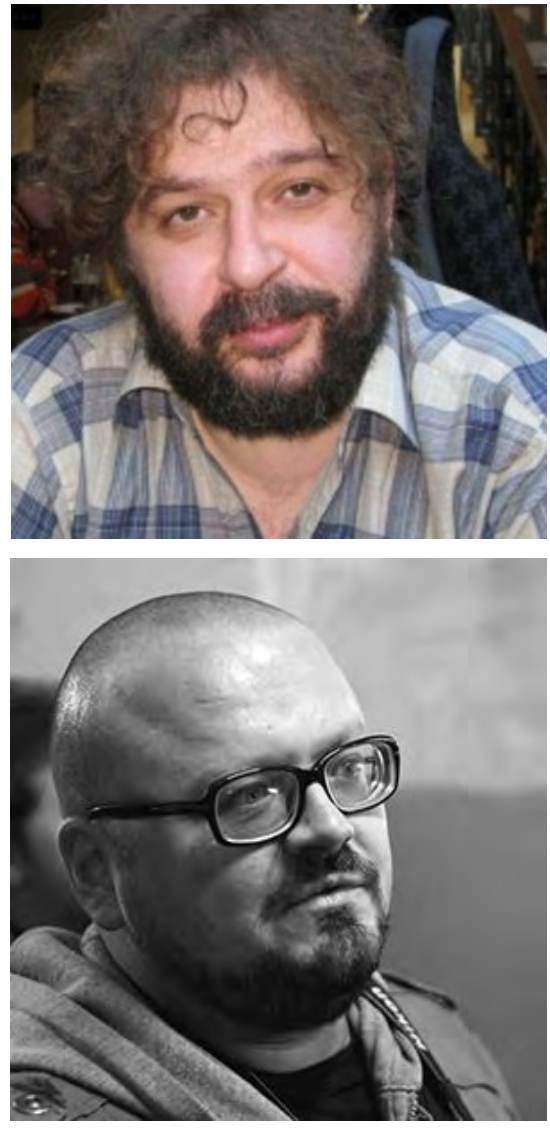

Igor Pilshchikov e Yan Levchenko, organizadores da obra. contexto intelectual europeu", afere as implicações extraterritoriais do Formalismo. Orientando-se por este prisma, os estudiosos apresentaram análises comparativas entre os formalismos russo e alemão, entre $o$ Formalismo e o Estruturalismo Tcheco, entre o Formalismo e os estudos literários poloneses. Também abordam a recepção do Formalismo na Sérvia e aponta aplicações de noções e conceitos desenvolvidos por Chklóvski no Decamerão, de Giovanni Boccaccio. A teórica francesa Catherine Depretto, pouco afeita a Roman Jakobson, mas interessada em Chklóvski e Tyniánov, fecha a seção com um estudo sobre a tradução e a recepção das ideias de Chklóvski na França desde a coletânea de Todorov, de 1965, até 2011.

A parte três é dedicada ao Formalismo Russo e o legado do escritor Andrei Biéli, o prolífico simbolista. Em linhas gerais, a seção procura estabelecer as semelhanças e diferenças entre o pensamento de Biéli e o de formalistas como Chklóvski, Jirmúnski, Tyniánov. No fundo, encena-se uma contraposição entre as abordagens do verso no âmbito do Simbolismo e do Formalismo; afora as muitas diferenças, que são em número maior do que as semelhanças, a valorização do aspecto sonoro do verso é um fio condutor que as une.

A quarta seção "Formalismo como vanguarda/vanguarda como Formalismo" apresenta uma rica contribuição aos estudos de dramaturgia, um tópico pouco explorado entre estudiosos do Formalismo Russo. Olga Burenina-Petrova aborda a tradições do teatro folclórico na perspectiva teórica de Vsevolod Meyerhold; numa perspectiva mais ampla, as estudiosas Siniti Murata e Irina Shatova focam nas ideias formalistas e no teatro de vanguarda russo nas primeiras décadas do século XX; a estudiosa italiana Nicoletta Misler, da Universidade de Nápoles, por sua vez, escreve sobre o sistema formal e o "desvio" na criação do alfabeto do corpo, algo bastante novo nos estudos formalistas. Dentre outros tantos que merecem destaque, observa-se ainda o ensaio de Dmitri Tokarev, que procu- 
ra correlacionar a "arte real" de Daniil Kharms, já conhecido do leitor brasileiro, com procedimentos do método formal.

A quinta parte, "Estudos formalistas sobre arte", a menor de todas, contém apenas três estudos. O primeiro deles é de John E. Bowlt, que há muitos anos se dedica às intersecções entre a escola formalista e as artes plásticas, com vasta produção nesta seara. Para o volume, Bowlt contribuiu com um estudo sobre a arte de Vassily Kandinsky e o método formalista. Marina Dmitriévna amplia a perspectiva ao abordar o método formalista na história da arte e outros âmbitos interdisciplinares. Nataliya Zlydneva encerra a seção com um artigo exploratório sobre as adaptações, transformações e recepções por que passaram algumas escolas de artes plásticas alemãs e vienenses na Rússia, desde o século XVIII. Numa perspectiva micro, a estudiosa articula, numa chave comparatista, as ideias sobre arte do vienense Alois Riegl e do russo Aleksandr Gabrichevski.

O sexto grupo, "Estudos formalistas sobre folclore", gira em torno das contribuições de Piotr Bogatyrióv e Vladimir Propp, os dois etnólogos mais importantes do Formalismo, embora muitas vezes a crítica não considere Propp propriamente um formalista e prefira associá-lo ao Estruturalismo. Tatiana Ivanova reconstitui arqueologicamente a relação entre os formalistas e os estudos sobre folclore no Instituto Russo de História da Arte [De Petrogrado/São Petersburgo]", antes de 1930; Svetlana Sorókina correlaciona conceitos desenvolvidos pelos formalistas russos com a noção de "teatro folclórico", de P. Bogatyrióv. Eketarina Velmezova, por sua vez, contrapõe as noções de "forma" em Bogatyrióv e em F. Saussure e também traz à baila noções como sincronia, diacronia e pancronia. Fecha a seção o estudo de Angelika Molnar sobre a recepção da obra de Propp pelos estudiosos do folclore húngaro moderno.

A sétima seção presta-se a duplo propósito: centra-se em uma abordagem imanente das teorias formalistas, mas também amplia as ideias principais do movimento para outras esferas. Pela perspectiva interdisciplinar, por exemplo, são exploradas as relações entre o Formalismo, Vladimir Nabókov 
e Mikhail Bakhtin. A seção é encerrada com um estudo que versa sobre a campanha antiformalista ocorrida em meados dos anos de 1930 (lembre-se que o ensaio "Monumento a um erro científico", publicado por Chklóvski é considerado o texto de encerramento do Formalismo Russo), a qual foi liderada pelos aparelhos ideológicos do estalinismo. O polêmico texto de Aleksandr Slonimski, uma espécie de "Carta ao leitor", no qual ele ataca frontalmente os críticos formalistas, é o fio condutor do ensaio, assinado por Elena Penskaia, da Faculdade de Filologia da Escola Superior Russa de Economia.

A última seção se volta para os estudos da prosa e da poesia no âmbito do Formalismo Russo. A maioria dos pesquisadores se vale de obras Khlébnikov, Tolstói e Proust para ilustrar conceitos formalistas. Muitos dos achados nada têm de novo, exceto o estudo sobre Proust. Além disso, essa derradeira parte traz informação valiosa no que tange à breve atividade dos críticos formalistas como professores e pesquisadores junto à Academia Estatal de Ciências e Artes de São Petersburgo.

A medir pela amplitude de temas, abordagens e metodologias, pode-se considerar esta a mais atual e extensa coletânea que atualiza e propõe novas perspectivas de estudos quanto a uma das mais importantes correntes da teoria literária do século $\mathrm{XX}$, que influenciou, entre outros, o Estruturalismo, a Estética da Recepção e a Semiótica da Escola de Paris.

A título de informação, no anexo abaixo, há a tradução do índice do livro apresentado, o qual contém o nome do autor seguido do título do ensaio. 


\section{Anexo}

\section{O século da teoria formalista: sua atualidade}

1. Viatchesláv Vsevolódovitch Ivánov: "O sistema formalista e sua interpretação nas ciências dos sécs. XX e XXI";

2. Aage Hansen-Löve: "Perspectivas Formalistas Russas: Logocentrismo ontem e hoje";

3. Igor P. Smirnóv: "A não-arte na teoria estética formalista";

4. Peter Steiner: "Arte, direito e ciências numa perspectiva modernista: Chklóvski, Schmitt e Popper";

5. Sergey Zenkin: "A energia intuitiva do Formalismo Russo";

6. Tomáš Glanc e Igor Pilshchikov: "O Formalismo Russo enquanto comunidade científica";

\section{O Formalismo Russo no contexto intelectual europeu}

1. Serguei Chugúnnikov: "Prolegômenos a uma análise comparativa entre os formalismos russo e alemão";

2. Ekaterina Dmítrieva: "Os alemães estão mesmo atrás de nós? Oskar Walzel e Victor Jirmúnski (episódio da história dos laços científicos russo-alemães)";

3. Vladímir Gubailóvski: "O formalismo de David Hilbert e o Formalismo Russo: a virada formalista";

4. Danuta Ulitska: "Estudos literários poloneses modernos: Círculos e escolas";

5. Michał Mrugalski: "A recepção polonesa da transferência do "priom" para o campo morfológico intelectual dos Formalismos Russo e Polonês";

6. Michal Kř́iž: "Do isolamento à concentração: a arqueologia da relação entre o Formalismo Russo e o Estruturalismo Tcheco entre polêmicas e discussões";

7. Aleksandar Petrov: "Como o Formalismo Russo conquistou a Sérvia"; 
8. Stefano Garzonio: "Viktor Chklóvski e Giovanni Boccaccio: sobre a história de um artigo pouco conhecido de Chklóvski"; 9. Catherine Depretto: "As ideias de Chklóvski na França: tradução e recepção (1965-2011)";

\section{O Formalismo Russo e o legado de Andrei Biéli}

1. Dina Magomedova: "Teoria dos símbolos nos escritos de V. Jirmúnski: entre Andrei Biéli e Viatchesláv Vsevolódovitch Ivánov";

2. Vladímir Novikov: "A poesia e a personalidade de Aleksandr Blok na interpretação de Andrei Biéli e do Formalismo Russo"; 3. Monika Spivak: "'A ressurreição da palavra' de Viktor Chklóvski e de Andrei Biéli";

4. Mikhail Odessky: "Arcaizantes e inovadores em conceitos teóricos de Iúri Tyniánov e Andrei Biéli";

5. Claudia Criveller: "O Formalismo Russo e a prosa autobiográfica experimental de Andrei Biéli";

6. Iúri Orlítski: "A estética como ciência exata: Os inscritos de Andrei Biéli dos anos 1900 sobre o verso russo à luz dos modernos estudos russos sobre versificação";

7. Dimitriy Torshilov: "Andrei Biéli sobre o Formalismo e a poética da pantomima no início dos anos 1920";

8. Robert Bird: "Oposição ao Formalismo, do Simbolismo ao Realismo Socialista: Pavel Miedvedev, Andrei Biéli e Boris Pasternak na virada da década de 1930";

\section{Formalismo como vanguarda/vanguarda como Formalismo}

1. Olga Burenina-Petrova: "Tradições do teatro folclórico e a Energia Potencial da arte no teatro de Vsevolod Meyerhold"; 2. Siniti Murata e Irina Shatova: "As ideias formalistas e o teatro de vanguarda russo nas primeiras décadas do século XX"; 3. Nicoletta Misler: "O sistema formal e o "desvio" na criação do alfabeto do corpo";

4. Dennis Ioffe: "A pragmática formalista: a questão do pro- 
cedimento de estranhamento (ostraniénie) e a superação da inércia do automatismo na vanguarda russa";

5. Lada Panova: "Os formalistas russos e os estudos sobre vanguarda: a questão da leitura compartilhada";

6. Dmitri Tokarev: "A 'arte real' de Daniil Kharms e o método formal";

7. Michael Meilakh: "Poesia e pintura: o caso da OBERIOU”;

\section{Estudos formalistas sobre arte}

1. John E. Bowlt: "Vassily kandinsky e o método formalista"; 2. Marina Dmitrievna: "O método formalista na história da arte e limites interdisciplinares";

3. Nataliya Zlydneva: "'Gesto' e 'Textura': Aleksandr S. Gabrichevski no espelho da pintura".

\section{Estudos formalistas sobre folclore}

1. Tatiana Ivanova: "A escola formalista e a folclorística dentro dos muros do Instituto Russo de História da Arte";

2. Svetlana Sorókina: "Ideias da escola formalista e o conceito de teatro folclórico de P. G. Bogatiryóv";

3. Ekaterina Velmezova: "P. Bogatiryóv vs F. de Saussure: sobre o problema de uma definição 'formal' de sincronia na Linguística e nos Estudos Folclóricos";

4. Angelika Molnar: "A recepção das obras de V. Propp no folclore húngaro moderno";

\section{Os formalistas em si e em contexto}

1. Lídia Sazonova e Mikhail Rodinson: "O primeiro Eikhenbaum: rumo ao Formalismo";

2. Elena Kapisson: "'Formas temporais' e o conceito de história: de S. L. Frank a B. M. Eichenbaum e I. N. Tyniánov";

3. Evguenia Ivanova: "Tchukovski e os formalistas";

4. Oleg Fedótov: "Ecos do Formalismo na mitopoética de Vladímir Nabókov"; 
5. Aleksander Galkin: "I. Tyniánov e S.N. Durilin: o mistério do diálogo de Púchkin";

6. Irina Popova: "Mikhail Bakhtin e o Formalismo Russo: sobre um caso despercebido de reaproximação";

7. Elena Penskaia: "Episódios da campanha antiformalista dos anos 1930: o caso Slonimski";

\section{Verso e prosa: a poética formal}

1. Willem Weststeijn: "O desnudamento do procedimento em Khlébnikov";

2. Tatiana M. Nikolaeva: "V. Chklóvski, Lev Tolstói e Marcel Proust";

3. Michela Venditti: "Análises do texto em prosa em estudos dos formalistas russos e dos membros do GAKhN";

4. Giuseppina Larocca: "A teoria da prosa nos anos 1920: Pumpianski e os "formalistas"';

5. Eric Martin: "A poética do recurso em A morte de Vazir-Mukhtar, de I. Tyniánov";

6. Ian Levchenko: "A pedra continua caindo. Sobre a dinâmica de gênero em Viktor Chklóvski após seu retorno do exílio";

7. Elena Trubetzkova: "'Olho e raquete, uma partida no Espaço': os códigos visuais do Formalismo Russo nos romances de Siguizmund Krjijanovski;"

8. Fiódor Dviniátin: "Distribuição das principais classes morfológicas de palavras no texto poético russo".

\section{Referências bibliográficas}

BERLINA, Alexandra. (edit. e trad.). Viktor Shklovsky: a Reader. Nova York: Bloomsbury, 2017.

ERLICH, Victor. Child of a Turbulent Century. Evanston: Northwestern University Press, 2006.

ERLICH, Victor. Russian Formalism: History - Doctrine. Haia: 
Mouton 1965.

JAKOBSON, Roman. "Vers une Science de l'art poétique". In: TODOROV, Tzvetan (org. e trad.) Théorie de la littérature: textes des formalistes russes. Paris: Éditions du Seuil, 1965.

KALININ, Ilya. "Viktor Shklovsky vs. Roman Jakobson. Poetic Language or Poetic Function of Language." Revista Enthymema, n. 19, 2017. (link: https://riviste.unimi.it/index.php/enthy-mema/article/view/9427/8901 .)

PILSHCHIKOV, Igor; LEVCHENKO, Yan. Epokha "ostraneniia". Russkii formalizm $i$ sovremennoe gumanitarnoe znanie ( $A$ era do "estranhamento": o Formalismo Russo e o conhecimento humanístico contemporâneo). Moscou: Novoe literaturnoe obozrenie, 2017.

SANMARTÍN ORTÍ, Pau. Otra historia del formalismo ruso. Madri: Lengua de trapo, 2008.

TODOROV, Tzvetan (org. e trad.) Théorie de la littérature: textes des formalistes russes. Paris: Éditions du Seuil, 1965.

Recebido em: 13/04/2020

Aceito em: 19/07/2020

Publicado em setembro de 2020 